\title{
Modelling Market Dynamics of Multi-Brand and Multi-Generational Products
}

Xiaohui Shi ${ }^{a, *}$ and Pattarin Chumnumpan ${ }^{b, c}$

${ }^{a}$ Kent Business School, University of Kent, Canterbury, United Kingdom, CT2 7FS;

Email: X.Shi-35@kent.ac.uk

${ }^{b}$ School of Business Administration, Bangkok University, Bangkok, Thailand, 10110;

'Christ Church Business School, Canterbury Christ Church University, Canterbury, United Kingdom, CT1 1NX

Email:pattarin.c@bu.ac.th

*corresponding author: Xiaohui Shi, $\underline{x . s h i-35 @ k e n t . a c . u k}$ 


\section{Abstract:}

This research develops a new product diffusion model for a product category that involves multiple brands and multiple generations. We examine our proposed model's validity through the case of Japanese mobile telecommunications services. In this product category, the model and its results give evidence of the coexistence of brand competition and generation substitution and show the importance of considering the two influences simultaneously. It also enables the analysis of both these influences to the end of gaining additional insights into the process of new product growth. The model proves reliable in forecasting both the overall market dynamics of a product category and the market performance of the individual brands and generations that belong to it.

Keywords: OR in marketing; new product diffusion; brand competition; technological substitution; mobile telecommunications service.

\section{Introduction}

Firms are placed under tremendous pressure by the constant threats presented by competitors and the rapid development of new technologies (Aytac et al., 2011). Examples of this abound: firms such as Motorola, Nokia, Blackberry, Apple, and Samsung have long been wrestling for position in the mobile phone market, stimulating the development of phones from early handsets with only basic calling features to today's 'smartphones' that enable users to access the Internet and run sophisticated applications. At the same time, the video game industry has witnessed eight consecutive console wars, during which firms have developed ever more sophisticated consoles, from simple and dedicated devices with a few embedded games to those that integrate cutting-edge hardware components, increased connectivity, and improved motion sensing technologies. And, in the PC sector, rivals Intel and AMD have competed in the market through many generations of new CPU technologies.

Firms that operate in the same product categories differ from each other in terms of their resources, innovativeness, and understanding of the market, which results in the differentiation of their products. These products, which are branded differently in the market, pose competitive threats to each other but, at the same time, can also effectively co-promote each other by driving forward the overall market and consumer appetites (Guseo et al., 2012; Libai et al., 2009b). As an example, by releasing the iPhone, Apple secured a tremendous share 
of the phone market; however, its competitors (such as Samsung) leveraged the buzz generated by the iPhone to quickly follow suit with competing products (Libai et al., 2009b). Furthermore, different firms respond to technological development and market change in different ways. Generational shifts in product categories usually provide firms with opportunities to calibrate or redesign their products, which can bring major changes to the dynamics of the whole market (Kreng et al., 2013; Michalakelis et al., 2010; Stremersch et al., 2010). For instance, due to the market success of its PlayStation, Sony replaced Nintendo as the industry leader in the $5^{\text {th }}$ generation of the game consoles, and went on to dominate the next generation with its PlayStation 2 (Liu, 2010); however, by showcasing motion controls and appealing to casual gamers, the Wii console enabled Nintendo to reclaim market leadership in the $7^{\text {th }}$ console war.

Recognizing the significant influences they exert on marketing decisions in increasingly dynamic environments, brand competition and generational substitution have been widely researched in the new product diffusion literature (Bass, 2004; Chatterjee et al., 2000; Meade et al., 2006; Peres et al., 2010; van Oorschot et al., 2018). However, our review also showed that, while the coexistence of these two factors has been frequently observed in practice, the existing literature has made an insufficient effort to integrate them into one diffusion model suited to understand and forecast the market dynamics. Furthermore, as the incorporation of more types of influence will unavoidably increase both model complexity and the difficulties in parameter estimation, many of the recent diffusion models (e.g., Yan et al., (2011), Kiesling et al. (2012), Negahban et al. (2014), Stummer et al. (2015), and Samuel Sale et al. (2017)) make use of simulations to understand the phenomenon and to generate new insights, which can limit the models' real-world relevance. Therefore, this study seeks to develop a diffusion model that can be used to explain and forecast the real-world diffusion phenomenon of multibrand and multi-generational products.

Building on the multi-generational model of Norton and Bass (1987) - with additional consideration given to the cross-brand influence-this study offers a new product diffusion model that simultaneously captures the effects of competition between different brands and those of technological substitution between successive generations in a product category. The proposed model enables the quantified examination and analysis of these two influences through real-world data, and the disaggregation of the estimated market potential of the product category across individual brands and generations. We therefore expect our model to aid both the theoretical understandings of new product growth and marketing planning in 
practice. We test the proposed model by means of data drawn from Japan's telecommunications sector. Our empirical analysis indicates that the model can accurately explain and forecast the market dynamics of the Japanese mobile telecommunications services.

The remainder of the paper is organized as follows. In section 2, we review the existing literature on new product diffusion models that consider brand competition and generational substitution, with a particular focus on the Bass model and its extensions. We then develop the new model in section 3 and we carry out model estimation based on data from the Japanese telecommunications industry in section 4 . We then further validate the model's predictive performance in section 5. Finally, we conclude this study in section 6 .

\section{Literature Review}

At an aggregated level, the market dynamics of first-purchase demand-as a typical diffusion process - usually follow a bell shaped curve that eventually decays due to the saturation of the potential market: that is, after the curve reaches its peak, demand can be expected to decline (Griliches, 1957). Following this observation, a number of models have been proposed; some originating from the desire to provide a means to better understand the phenomenon, others simply driven from the desire to fit the real world data (Meade et al., 2006). As the pioneering work in this field, the Bass model (Bass, 1969) represents this phenomenon by generalizing the two main drivers of new product growth as the innovation effect (which can also be explained as the customers' inner intentions to adopt or as the mass media effect) and the imitation effect (which can also be explained as the influence of others in the social system, as the social contagion effect, or as the word-of-mouth effect); it can be explained in the following form:

$$
\frac{d F(t)}{d t}=(p+q F(t))(1-F(t))
$$

where $p$ is the coefficient for innovation, $q$ is the coefficient for imitation, and $F(t)$ is the market penetration level at time $t$. Solving Equation (1), we obtain:

$$
F(t)=\frac{1-\exp (-(p+q) t)}{1+(q / p) \exp (-(p+q) t)}
$$

Note that, although the Bass model was developed to calculate the aggregated market growth of a product category, it serves as the conceptual foundation of the main body of literature on new product growth models (Chatterjee et al., 2000; Peres et al., 2010). 
All markets are competitive and dynamic. Although a new product may enjoy a monopoly status in its market when (or soon after) it is launched, other firms will quickly market competing products. In terms of competitive product diffusion models, the main body of the literature considers a product brand's market performance as the result of the combination of within-brand and cross-brand influences, and this phenomenon is modelled and studied by extending the Bass model to others that can be generalized to either Equation (3) or Equation (4) (Peres et al., 2010):

$$
\begin{aligned}
& \frac{d N_{i}(t)}{d t}=\left(p_{i}+q_{i} \frac{N_{i}(t)}{m}+\sum_{j \neq i} q_{i, j} \frac{N_{j}(t)}{m}\right)\left(m-N_{i}(t)\right) \\
& \frac{d N_{i}(t)}{d t}=\left(p_{i}+q_{i} \frac{N_{i}(t)}{m_{i}}+\sum_{j \neq i} q_{i, j} \frac{N_{j}(t)}{m_{j}}\right)\left(m_{i}-N_{i}(t)\right)
\end{aligned}
$$

The difference between the two is found in whether the market potentials of the competing brands overlap (Equation (3), e.g., Libai et al. (2009a)) or not (Equation (4), e.g., Parker et al. (1994)). Whereas the former setting leads to different brands competing for market share, the latter is more likely to lead to a steady-state condition in which competing products coexist in the marketplace by targeting different customer niches. In Equations (3) and (4), $N_{i}(t)$ is the cumulative number of users of brand $i$ at time $t ; p_{i}$ and $q_{i}$ are the corresponding coefficients for the innovation and imitation effects for brand $i$ of its own (i.e., within-brand influence); and (more importantly) $q_{i, j}$ is introduced to explain the cross-brand influence of brand $j$ on the diffusion rate of brand $i$. Parameter $q_{i, j}$ is assumed and analysed in different ways in the existing literature: some studies (e.g., Savin et al. (2005) consider $q_{i, j}$ to differ significantly between any two brands; others (e.g., Krishnan et al. (2000)) assume that within-brand influence equals cross-brand influence (i. e. , $q_{i, j}=q_{i}$ ); and others still (e.g., Libai et al. (2009a)) argue that cross-brand influence is not so important and can be ignored (i. e., $q_{i, j}=0$ ). The reported value of parameter $q_{i, j}$ can also be positive, negative, or zero in different cases, indicating that brands can speed up, delay, or have no impact on each other's market performance (Chatterjee et al., 2000).

Furthermore, products are usually substituted by newer generations with more advanced attributes that can create new market potential and entice existing users to update, so that each successive substitution boosts market demand. Scholars have explored various approaches to modelling and studying the market performance of products that go through multiple generations. For instance, Mahajan and Muller (1996) modified the Bass model to 
study the number of generations of IBM mainframes in use, and Kim and Srinivasan (2003) introduced a choice model to study customer purchase decisions based on the utility of different product generations. More recently, Tsai (2013) developed an extended Gompertz model suited to predict the market growth of generations of LCD TVs, Kreng and Wang (2013) constructed a dynamic system model suited to analyse the case of Nike Golf clubs, and Guo and Chen (2018) developed a new product diffusion model suited to study multi-generational product diffusion in the presence of strategic consumers. Despite these examples of progress, our review of the literature suggests that the Norton-Bass model (Norton et al., 1987) remains the most cited and tested multi-generational product diffusion growth model to date. The key concept embedded in this model is that later generations 'plunder' the customer bases of earlier versions with which they compete in the market. To illustrate this model, the units in use of two product generations in time period $t$ (i.e., $S_{1}(t)$ and $S_{2}(t)$ ) can be explained by Equations (5) and (6):

$$
\begin{aligned}
& S_{1}(t)=F_{1}(t) m_{1}\left(1-F_{2}\left(t-\tau_{2}\right)\right) \\
& S_{2}(t)=F_{2}\left(t-\tau_{2}\right)\left(m_{2}+F_{1}(t) m_{1}\right)
\end{aligned}
$$

where $\tau_{2}$ is the release time of the second generation; and $m_{1}$ and $m_{2}$ represent the market potential for the two generations respectively. In both equations $F_{l}(t)$ is the diffusion rate of a generation $l$ product at time $t$, which takes the form shown below, based on the Bass model.

$$
\begin{aligned}
& F_{l}(t)=\frac{1-\exp \left(\left(-\left(p_{l}+q_{l}\right)\left(t-\tau_{l}\right)\right)\right)}{1+\left(q_{l} / p_{l}\right) \exp \left(\left(-\left(p_{l}+q_{l}\right)\left(t-\tau_{l}\right)\right)\right)}, \text { when } t>\tau_{l} \\
& F_{l}(t)=0, \text { when } t \leq \tau_{l}
\end{aligned}
$$

In Equation (7), $p_{l}$ and $q_{l}$ are the coefficients for innovation and imitation for generation $l$, which is consistent with the Bass model.

Despite their rich respective literatures, little attention has been dedicated to integrating brand competition and generation substitution into a single product diffusion model suited to understand and predict market dynamics, although some seemingly related models can be found. For instance, building on the Norton-Bass model, Kim et al. (2000) modelled the market dynamics of inter-related multiple-generation product categories; Jun et al. (2011) also developed a choice-based model that enables the differentiation of first-time and replacement purchase behaviours in competitive markets. It should also be noted that the two models of Kim et al. (2000) and Jun et al. (2011) were developed for contexts that differed both from each 
other and from the purpose of this study. More specifically, Kim's model was developed to study inter-related product categories (e.g., Pagers, Cellular Phones, and Cordless Telephones 2), rather than competing brands in the same category, and the Jun-Kim model studies general replacement demand rather than generation substitution (i.e., in the absence of product upgrade). Although one may apply the multi-categories and multi-generational model developed by Kim et al. (2000) to multi-brand and multi-generational cases, its practical value can be constrained by the large number of parameters that need to be estimated. As in their paper, 16 parameters need to be estimated when studying the wireless telecom service industry in Hong Kong with three product categories of only one or two generations in use; i.e., Pagers (one generation), Cellular Phones (two generations), and Cordless Telephones 2 (one generation). Furthermore, both of the above models deal with competition effects in ways that deviate from the models used in the main body of the competitive diffusion literature, which consider both within- and cross-brand influences on diffusion rates. Kim's model considers the inter-category competition that mutually affects each product category's market potential rather than the diffusion rate, while Jun and Kim employ a choice model to explain user purchase preferences between brands.

\section{The Suggested Model}

Let us assume that a product category is commercialized by different firms under $K$ competing brands, and that the product category has gone through $L$ successive generations due to the development of the relevant technologies. In general, we can consider that, as each generation's products perform better than those of their predecessors, those customers that use later generation products will not revert to using earlier generation ones. 
Table 1: Summary of Notations in the Suggested Model

\begin{tabular}{cl}
\hline $\begin{array}{c}\text { Notation } \\
K\end{array}$ & Number of competing brands in the product category; \\
$L$ & Number of successive generations in the product category; \\
$\tau_{k, l}$ & Actual release time of brand $k$ generation $l ;$ \\
$S_{k, l}$ & Unit in use for brand $k$ generation $l ;$ \\
$N_{k, l}^{\text {new }}$ & New users that brand $k$ generation $l$ has attracted; \\
$N_{i, l-1, k, l}^{\text {upgrade }}$ & Users who have upgraded from brand $i$ generation $l-1$ to brand $k$ generation $l ;$ \\
$u_{k, l, i, l+1}$ & Substitution rate between brand $k$ generation $l$ and brand $i$ generation $l+1 ;$ \\
$x_{k, l}$ & Diffusion rate of brand $k$ generation $l ;$ \\
$F_{k, l}$ & User understanding of the characteristics of brand $k$ generation $l ;$ \\
$p_{k, l}$ & Coefficient of innovation effect for brand $k$ generation $l ;$ \\
$q_{k, l}$ & Coefficient of imitation effect for brand $k$ generation $l ;$ \\
$m_{k, l}$ & New and unique market potential of brand $k$ due to the release of its $l^{t h}$ \\
$b$ & generation; \\
$c$ & Coefficient for cross-brand diffusion effect; \\
\hline
\end{tabular}

$S_{k, l}(t)$ denotes the number of units from brand $k$ generation $l$ of this product category in use at time $t$. Ultimately, we can consider that $S_{k, l}(t)$ may be influenced by three types of user dynamics. Brand $k$ generation $l$ could first, attract new users to the product category; and, second, attract upgraders from previous generation products (although, for simplicity, we do not consider 'leapfrogging' in this study). Third, users of brand $k$ generation $l$ (both new users and upgraders, as discussed above) are likely to further upgrade when a newer generation of the product category comes on to the market. To conclude, we can propose Equation (9) for $S_{k, l}(t):$

$$
S_{k, l}(t)=\left(N_{k, l}^{\text {new }}(t)+\sum_{1 \leq i \leq K} N_{i, l-1, k, l}^{\text {upgrade }}(t)\right)\left(1-\sum_{1 \leq i \leq K} u_{k, l, i, l+1}(t)\right)
$$

in which $N_{k, l}^{\text {new }}(t)$ indexes the number of new users that brand $k$ has attracted by time $t$ due to the release of generation $l$, and $N_{i, l-1, k, l}^{\text {upgrade }}(t)$ represents the number of users who have upgraded from brand $i$ generation $l-1$ to brand $k$ generation $l$ by time $t$. Thus, $\sum_{1 \leq i \leq K} N_{i, l-1, k, l}^{\text {upgrade }}(t)$ indicates the total number of upgraders that brand $k$ generation $l$ has attracted. Then, $u_{k, l, i, l+1}(t)$ indicates the substitution rate between brand $k$ generation $l$ and brand $k$ generation $l+1$; i.e., the percentage of brand $k$ generation $l$ users who have upgraded to brand $i$ generation $l+1$ at time $t$, so that $\sum_{1 \leq i \leq K} u_{k, l, i, l+1}(t)$ measures the overall percentage 
of brand $k$ generation $l$ users who have upgraded to the next generation. To view it from another perspective, we can expand Equation (9) to get:

$$
\begin{aligned}
S_{k, l}(t)=\left(N_{k, l}^{\text {new }}(t)\right. & \left.+\sum_{1 \leq i \leq K} N_{i, l-1, k, l}^{\text {upgrade }}(t)\right) \\
& -\left(N_{k, l}^{\text {new }}(t)+\sum_{1 \leq i \leq K} N_{i, l-1, k, l}^{\text {upgrade }}(t)\right) \sum_{1 \leq i \leq K} u_{k, l, i, l+1}(t)
\end{aligned}
$$

In this equation, $\left(N_{k, l}^{\text {new }}(t)+\sum_{1 \leq i \leq K} N_{i, l-1, k, l}^{\text {upgrade }}(t)\right)$ is the total number of users that brand $k$ generation $l$ has attracted by time $t$; and the latter part-i.e., $\left(N_{k, l}^{\text {new }}(t)+\right.$ $\left.\sum_{1 \leq i \leq K} N_{i, l-1, k, l}^{\text {upgrade }}(t)\right) \sum_{1 \leq i \leq K} u_{k, l, i, l+1}(t)-$ is the number of users who have abandoned the product due to upgrading by time $t$. Then (based on this latter part), we can easily develop Equation (11) for the number of upgraders from brand $k$ generation $l$ to each of the next generation brands:

$$
N_{k, l, i, l+1}^{\text {upgrade }}(t)=\left(N_{k, l}^{\text {new }}(t)+\sum_{1 \leq i \leq K} N_{i, l-1, k, l}^{\text {upgrade }}(t)\right) u_{k, l, i, l+1}(t)
$$

It appears that the equation for $N^{\text {upgrade }}$ is a recurrent function that, specifically, gives $N_{k, 1, i, 2}^{\text {upgrade }}(t)=N_{k, 1}^{\text {new }}(t) u_{k, 1, i, 2}(t)$ when $l=1$ (because the first generation attracts no upgraders, $\left.N_{k, 0, i, 1}^{\text {upgrade }}(t)=0, \forall i, k\right)$. After substituting Equation (11) into Equation (9) (or into Equation $(10))$, to solve $S_{k, l}(t)$, we only need to know the answers to $N_{k, l}^{n e w}(t)$ and $u_{k, l, i, l+1}(t)$, which we will discuss below.

To model $N_{k, l}^{n e w}(t)$, we first consider that the release of each new generation of each brand ultimately creates a new and unique market potential. The setting of a respective market potential for each generation is widely accepted, but such setting for each brand receives mixed views (Peres et al., 2010). As indicated in our literature review, some scholars (e.g., Libai et al. (2009a)) considered a shared market potential in which all brands to compete, others (e.g., Parker et al. (1994)) suggested for each brand a respective market potential that cannot be accessed by others. Here, the new market potential for brand $k$ generation $l$ is denoted as $m_{k, l}$. Then, we assume that those potential customers will eventually become users of the new brand, although they may temporally adopt other competing brands during the process making a temporarily shared market potential possible in the process. In other words, although the setting of $m_{k, l}$ indexes the respective market potential for each brand, it still enables the market potential to be shared with others during the diffusion process in order to 
capture the customer churn between brands. The above assumption also implies an eventual steady-state condition in which different brands coexist with their respective niche customers, who are attracted by their differentiated product offerings. Thus, as time approaches $+\infty$ :

$$
\sum_{j=1}^{L} S_{k, j}(t)=\sum_{j=1}^{L} m_{k, j}
$$

Then, if we let $x_{k, l}(t)$ be the diffusion rate for brand $k$ generation $l$ at time $t$, the product will generate $x_{k, l}(t) m_{k, l}$ new users from its own market potential by time $t$. Beside within-brand adoption, we also follow the competitive product diffusion literature (Chatterjee et al., 2000; Peres et al., 2010) and allow for some market growth of brand $k$ generation $l$ from cross-brand adoption-i.e., where brand $k$ generation $l$ attracts users of other brands. Setting $b$ as the coefficient for the cross-brand diffusion effect-indicating the level of diffusion influence of one brand on its competitors' markets ${ }^{1}$ - we have a model of $N_{k, l}^{\text {new }}(t)$ in the following form:

$$
N_{k, l}^{\text {new }}(t)=x_{k, l}(t) m_{k, l}+\sum_{i \neq k}\left(b x_{k, l}(t)\left(1-x_{i, l}(t)\right) m_{i, l}\right)
$$

in which $\left(1-x_{i, l}(t)\right) m_{i, l}$ indicates the unique market potential of brand $i$ generation $l$ that has not been penetrated by its own diffusion influence. When $b>0, b x_{k, l}(t)$ represents the actual diffusion rate of brand $k$ generation $l$ on the remaining market potential of other brands (i.e., those potential customers who have not adopted their designated products), hence, $\sum_{i \neq k}\left(b x_{k, l}(t)\left(1-x_{i, l}(t)\right) m_{i, l}\right)$ indicates the total number of users that brand $i$ generation $l$ has temporally plundered from its competing products. So, our model interpretation regarding the cross-brand diffusion effect could also account for customer switching during the process. Note that, in practice, the value of $b$ can also be negative or zero, as brand competition means that one brand can delay or have no impact on the market growth of others in different cases. Such setting of $b$ is consistent with the findings regarding the competition effect in the literature (Chatterjee et al., 2000).

1 This study assumes constant values for cross-brand diffusion effect $b$, and for cross-brand communication effect $c$ (see Equation (16) and the corresponding model elaboration). In reality, however, the values can differ across generations and between brands. For instance, different brands may have different levels of influence over others due to brand awareness and brand reputation; such influences may change across generations and over time.

To consider such scenarios, in Equation (13), $b$ shall be substituted with $b_{k, l}$ to indicate the level of diffusion influence of brand $k$ generation $l$ on its competitors' markets; similarly, in Equation (16), $c$ shall be substituted with $c_{k, l}$ to indicate the extent to which customer understanding of other products on the market will complement their understanding of brand $k$ generation $l$. Note that the consideration of such scenarios will significantly increase model complexity, requiring more data input and computing power for empirical analysis. 
We consider each product's users' upgrading behaviours to be driven by the diffusion influences of its next generation offerings. For substitution between two generations of the same brand (i.e., upgrade from brand $k$ generation $l$ to brand $k$ generation $l+1$ ), we let $u_{i, l, k, l+1}(t)$ equal the diffusion rate of the later generation (Norton et al., 1987) - thus yielding Equation (14). For the substitution between two generations of different brands (i.e., upgrade from brand $k$ generation $l$ to brand $i$ generation $l+1)$, we use Equation (15) for $u_{i, l, k, l+1}(t)$. Here, $x_{i, l+1}(t)$ indexes the diffusion rate of brand $i$ generation $l+1$, and $\left(1-x_{k, l+1}(t)\right)$ indicates the percentage of the unique market potential of brand $k$ generation $l+1$ that has not been penetrated by its own diffusion influences. The cross-brand diffusion effect $b$ in Equation (15) is consistent with its explanation in Equation (13).

$$
\begin{aligned}
& u_{k, l, i, l+1}(t)=x_{i, l+1}(t), \text { when } i=k \\
& u_{k, l, i, l+1}(t)=b x_{i, l+1}(t)\left(1-x_{k, l+1}(t)\right), \text { when } i \neq k
\end{aligned}
$$

In Equations (13), (14), and (15), $x_{k, l}(t)$ - the diffusion rate of brand $k$ generation $l-$ is likely to increase over time, due to the customers' increasing understanding of product characteristics. Building on the competitive diffusion literature, we consider the market growth of one product in a category to also be influenced by its direct market competitors, i.e., other brands' products of the same generation. Therefore, the actual diffusion rate for brand $k$ generation $l$ should be adjusted based on the influences of those brands that compete with it in the market, which leads us to use Equation (16) for $x_{k, l}(t)$.

$$
x_{k, l}(t)=F_{k, l}(t)+\left(1-F_{k, l}(t)\right) c \sum_{i \neq k} F_{i, l}(t)
$$

In Equation (16), $F_{k, l}\left(0 \leq F_{k, l}<1\right)$ represents customer understanding of the characteristics of brand $k$ generation $l . c$ is defined as the coefficient for cross-brand communication effect, which explains the extent to which customer understanding of other products on the market will complement their understandings of their current product. As with parameter $b$, the value of parameter $c$ can be positive, negative, or zero, which means that the competing brands can have positive, negative, or no impacts on user understanding of a product.

We consider user understandings of a product's characteristics to be driven by the innovation and imitation effects, as generalized and described in the Bass model, so $F_{k, l}$ can take the following form: 


$$
\begin{aligned}
& F_{k, l}(t)=\frac{1-\exp \left(-\left(p_{k, l}+q_{k, l}\right)\left(t-\tau_{i, l}\right)\right)}{1+\left(q_{k, l} / p_{k, l}\right) \exp \left(-\left(p_{k, l}+q_{k, l}\right)\left(t-\tau_{i, l}\right)\right)} \text {, when } t>\tau_{i, l} \\
& F_{k, l}(t)=0, \text { when } t \leq \tau_{i, l}
\end{aligned}
$$

where $p_{k, l}$ and $q_{k, l}$ are the corresponding coefficients for innovation and imitation effects; and $\tau_{i, l}$ is the actual release time of brand $k$ generation $l$. In terms of parameters $p_{k, l}$ and $q_{k, l}$, the multi-generational product diffusion model literature provides different views on whether their values change across generations. Some researchers (e.g., Norton and Bass (1987), Mahajan and Muller (1996), Kim et al. (2000)) argued that the difference in their values across generations should be minimal; others (e.g., Pae and Lehmann (2003)) suggested that $p$ and $q$ should be considered independently for each generation; in between these two groups, a few researchers (e.g., Islam et al. (1997) and Jiang et al. (2012)) also proposed constant $p$ and independent $q$ across generations. For simplicity, this study adopts the first view, leading to:

$$
\begin{aligned}
& p_{k, 1}=\cdots=p_{k, l}=\cdots=p_{k, L} \\
& q_{k, 1}=\cdots=q_{k, l}=\cdots=q_{k, L}
\end{aligned}
$$

This decision can be supported by the work of Stremersch et al. (2010), who examined 39 distinct technology generations of 12 products and concluded that, although newer product generations may show faster diffusion than older ones, such intergeneration acceleration occurs due to a shorter takeoff time driven by technology vintage (i.e., the passage of time), but not with respect to diffusion parameters $p$ and $q$. Indeed, independent $p$ and $q$ values across generations may further improve model accuracy, but will also increase model complexity, the required data inputs, and the computing power for empirical analysis. Researchers and practitioners should decide carefully after weighing the pros and cons.

After substituting Equations (11) and (13) - (20) into Equation (9) (or Equation (10)), we have the proposed model. As an example, the complete model for a case with two brands and two generations can be represented in the following format:

$$
\begin{aligned}
S_{1,1}(t)=\left(F_{1,1}(t)\right. & \left.m_{1,1}+b F_{1,1}(t)\left(1-F_{2,1}(t)\right) m_{2,1}\right)\left(1-\left(F_{1,2}(t)+\left(1-F_{1,2}(t)\right) c F_{2,2}(t)\right)\right. \\
& \left.-b\left(F_{2,2}(t)+\left(1-F_{2,2}(t)\right) c F_{1,2}(t)\right)\left(1-\left(F_{1,2}(t)+\left(1-F_{1,2}(t)\right) c F_{2,2}(t)\right)\right)\right)
\end{aligned}
$$




$$
\begin{aligned}
S_{2,1}(t)=\left(F_{2,1}(t)\right. & \left.m_{2,1}+b F_{2,1}(t)\left(1-F_{1,1}(t)\right) m_{1,1}\right)\left(1-\left(\left(F_{2,2}(t)+\left(1-F_{2,2}(t)\right) c F_{1,2}(t)\right)\right)\right. \\
& \left.-b\left(F_{1,2}(t)+\left(1-F_{1,2}(t)\right) c F_{2,2}(t)\right)\left(1-\left(F_{2,2}(t)+\left(1-F_{2,2}(t)\right) c F_{1,2}(t)\right)\right)\right) \\
S_{1,2}(t)=\left(F_{1,2}(t)\right. & \left.m_{1,2}+b F_{1,2}(t)\left(1-F_{2,2}(t)\right) m_{2,2}\right) \\
& +\left(F_{1,1}(t) m_{1,1}+b F_{1,1}(t)\left(1-F_{2,1}(t)\right) m_{2,1}\right)\left(F_{1,2}(t)+\left(1-F_{1,2}(t)\right) c F_{2,2}(t)\right) \\
& +\left(F_{2,1}(t) m_{2,1}+b F_{2,1}(t)\left(1-F_{1,1}(t)\right) m_{1,1}\right) b\left(F_{1,2}(t)\right. \\
& \left.+\left(1-F_{1,2}(t)\right) c F_{2,2}(t)\right)\left(1-\left(F_{2,2}(t)+\left(1-F_{2,2}(t)\right) c F_{1,2}(t)\right)\right) \\
S_{2,2}(t)=\left(F_{2,2}(t)\right. & \left.m_{2,2}+b F_{2,2}(t)\left(1-F_{1,2}(t)\right) m_{1,2}\right) \\
+ & \left(F_{2,1}(t) m_{2,1}+b F_{2,1}(t)\left(1-F_{1,1}(t)\right) m_{1,1}\right)\left(F_{2,2}(t)+\left(1-F_{2,2}(t)\right) c F_{1,2}(t)\right) \\
+ & \left(F_{1,1}(t) m_{1,1}+b F_{1,1}(t)\left(1-F_{2,1}(t)\right) m_{2,1}\right) b\left(F_{2,2}(t)\right. \\
+ & \left.\left(1-F_{2,2}(t)\right) c F_{1,2}(t)\right)\left(1-\left(F_{1,2}(t)+\left(1-F_{1,2}(t)\right) c F_{2,2}(t)\right)\right)
\end{aligned}
$$

where:

$$
\begin{aligned}
& F_{k, l}(t)=\frac{1-\exp \left(-\left(p_{k, l}+q_{k, l}\right)\left(t-\tau_{i, l}\right)\right)}{1+\left(q_{k, l} / p_{k, l}\right) \exp \left(-\left(p_{k, l}+q_{k, l}\right)\left(t-\tau_{i, l}\right)\right)}, \text { when } t>\tau_{i, l} \\
& F_{k, l}(t)=0, \text { when } t \leq \tau_{i, l}
\end{aligned}
$$

In practice, the parameters to be estimated for the model are as follows: $K$ parameters for $p$ and for $q$; $K \times L$ parameters for $m$; one parameter each for $b$, and for $c$, so the total number of parameters to be estimated is $2 K+K L+2$. Thus, for instance, 10 parameters will need to be estimated for a product category with two brands and two generations, and 20 parameters will need to be estimated for a product category with three brands and four generations.

When both $b=0$ and $c=0$, the influences regarding brand competition in our proposed model (i.e., the cross-brand diffusion and cross-brand communication effects) are both eliminated, leaving us with $x_{k, l}(t)=F_{k, l}(t), u_{i, l-1, k, l}(t)=x_{k, l}(t)=F_{k, l}(t)$ (when $i=k$ ), and $u_{i, l-1, k, l}(t)=x_{k, l}(t)=0$ (when $i \neq k$ ), so that Equation (9) becomes simplified to:

$$
S_{k, l}(t)=\left(F_{k, l}(t) m_{k, l}+N_{k, l-1, k, l}^{u p g r a d e}(t)\right)\left(1-F_{k, l+1}(t)\right)
$$

Then substituting Equation (11) into Equation (21), we can obtain: 


$$
\begin{aligned}
S_{k, l}(t)=\left(F_{k, l}(\right. & t) m_{k, l}+F_{k, l}(t) F_{k, l-1}(t) m_{k, l-1} \\
& +F_{k, l}(t) F_{k, l-1}(t) F_{k, l-2}(t) m_{k, l-2}+\cdots \\
& \left.+F_{k, l}(t) F_{k, l-1}(t) F_{k, l-2}(t) \ldots F_{k, 1}(t) m_{k, 1}\right)\left(1-F_{k, l+1}(t)\right)
\end{aligned}
$$

where $F_{k, l}(t)$ remains in the form of Equations (17) and (18). Note that Equation (22) actually indicates $K$-independent Norton-Bass models, each of which explains one brand in the product category. Therefore, we can conclude that, if we exclude the brand competition elements, our model is consistent with the Norton-Bass model. We see this as an important advantage of our model, due to the Norton-Bass model's wide acceptance and applicationby linking it and comparing it with the Norton-Bass model, our new model can offer findings and insights not presented in prior studies.

\section{Empirical Analysis}

\subsection{The Data - the Japanese Mobile Telecommunications Industry}

In most countries or regions, mobile telecommunications services are provided by multiple network providers using different network standards or marketing strategies. For instance, people in the US can choose between network options that include Verizon Wireless, AT\&T, T-Mobile, and so on, while the UK market is mainly dominated by EE, O2, Vodafone, and 3. Meanwhile, as a typical growing IT industry, the mobile telecommunications sector has witnessed several generational changes in its core technologies, which are commonly known as $1 \mathrm{G}, 2 \mathrm{G}, 3 \mathrm{G}$, and $4 \mathrm{G}$ standards. Each generation has offered significantly improved utility over its predecessor - for instance, the $2 \mathrm{G}$ network uses digital signals rather than the analogue ones used by the $1 \mathrm{G}$, which can provide greater penetration and extra data services for mobiles (e.g., SMS text messages).

The Japanese mobile telecommunications industry is one of the most advanced in the world. Japan has successfully developed and commercialized four generations of mobile networks - it was the first in the world to launch 1 G mobile phone services (in 1979), and among the first to release commercial 2G, 3G, and 4G networks (in 1993, 2001, and 2010). In terms of standards, service providers, and phone manufacturers, Japan also has a relatively self-contained and self-sufficient domestic mobile telecommunications industry (Kushida, 2002)-for instance, PDC (Personal Digital Cellular) is a $2 \mathrm{G}$ mobile network standard developed and used exclusively in Japan. These characteristics mean that adopting Japan's 
industry as our study setting enabled us to exclude the influence of global diffusion (e.g., Albuquerque et al. (2007)) from our analysis.

During our studied period, the Japanese mobile telecommunications market was dominated by three network providers: NTT DoCoMo, au, and Softbank. Although EMOBILE also operated in the Japanese market, it had a market share of less than $3 \%$ at most, and thus was too small to consider. The data we employed in this study was sourced from the Telecommunications Carriers Association of Japan, and includes the numbers of service subscribers differentiated by network providers and by product generations (see Figure 1). The data was updated monthly during our studied period (January 1996 - November 2010) which mainly covered the market dynamics of the 2G and 3G services. For NTT and au, the data set also contains some aggregated data for $1 G$ and $2 G$ subscriptions. Further details pertaining to the data set can be found in Table 2 .

Table 2: Data

\begin{tabular}{|c|c|c|c|}
\hline Company & $\begin{array}{c}\text { Available } \\
\text { Product } \\
\text { Data }\end{array}$ & Data Period & Description \\
\hline \multirow[t]{3}{*}{ NTT } & $1 \mathrm{G}+2 \mathrm{G}$ & $\begin{array}{c}(1996.01-2000.10) \\
58 \text { Data Points }\end{array}$ & \multirow{3}{*}{$\begin{array}{l}\text { Established in } 1952 \text { as a state-owned } \\
\text { monopoly corporation, NTT was the world's } \\
\text { largest telecommunications company in } \\
\text { terms of revenue. } \\
\text { NTT used PDC and WCDMA as its } 2 \mathrm{G} \text { and } \\
\text { 3G standards during our study period. }\end{array}$} \\
\hline & $2 \mathrm{G}$ & $\begin{array}{c}(2000.11-2010.11) \\
121 \text { Data Points }\end{array}$ & \\
\hline & $3 G$ & $\begin{array}{c}(2001.10-2010.11) \\
110 \text { Data Points }\end{array}$ & \\
\hline \multirow[t]{3}{*}{$\mathrm{au}$} & $1 G+2 G$ & $\begin{array}{c}(1996.01-2000.10) \\
58 \text { Data Points }\end{array}$ & \multirow{3}{*}{$\begin{array}{l}\text { au was formed by a series of mergers of } \\
\text { several corporations, including DDI, KDD, } \\
\text { and IDO. } \\
\text { In contrast to NTT and Softbank, au used } \\
\text { CDMAOne and CDMA1X for its } 2 \mathrm{G} \text { and 3G } \\
\text { standards. }\end{array}$} \\
\hline & $2 \mathrm{G}$ & $\begin{array}{c}(2000.11-2010.11) \\
121 \text { Data Points }\end{array}$ & \\
\hline & $3 G$ & $\begin{array}{c}(2002.04-2010.11) \\
\text { 104 Data Points }\end{array}$ & \\
\hline \multirow[t]{2}{*}{ SOFTBANK } & $2 \mathrm{G}$ & $\begin{array}{c}(1996.01-2010.02) \\
\text { 170 Data Points }\end{array}$ & \multirow{2}{*}{$\begin{array}{l}\text { Originally founded in } 1981 \text { as the mobile } \\
\text { phone division of Japan Telecom, it acquired } \\
\text { several local companies from DPG and DT } \\
\text { Gina in a major merger in } 1999 \text {. Before } \\
\text { becoming Softbank Mobile in 2006, the } \\
\text { consolidated firm was called J-PHONE and } \\
\text { then Vodafone Japan. } \\
\text { The company used the same 2G and 3G } \\
\text { standards as NTT. }\end{array}$} \\
\hline & $3 G$ & $\begin{array}{c}\text { (2002.12 - 2010.11) } \\
96 \text { Data Points }\end{array}$ & \\
\hline
\end{tabular}




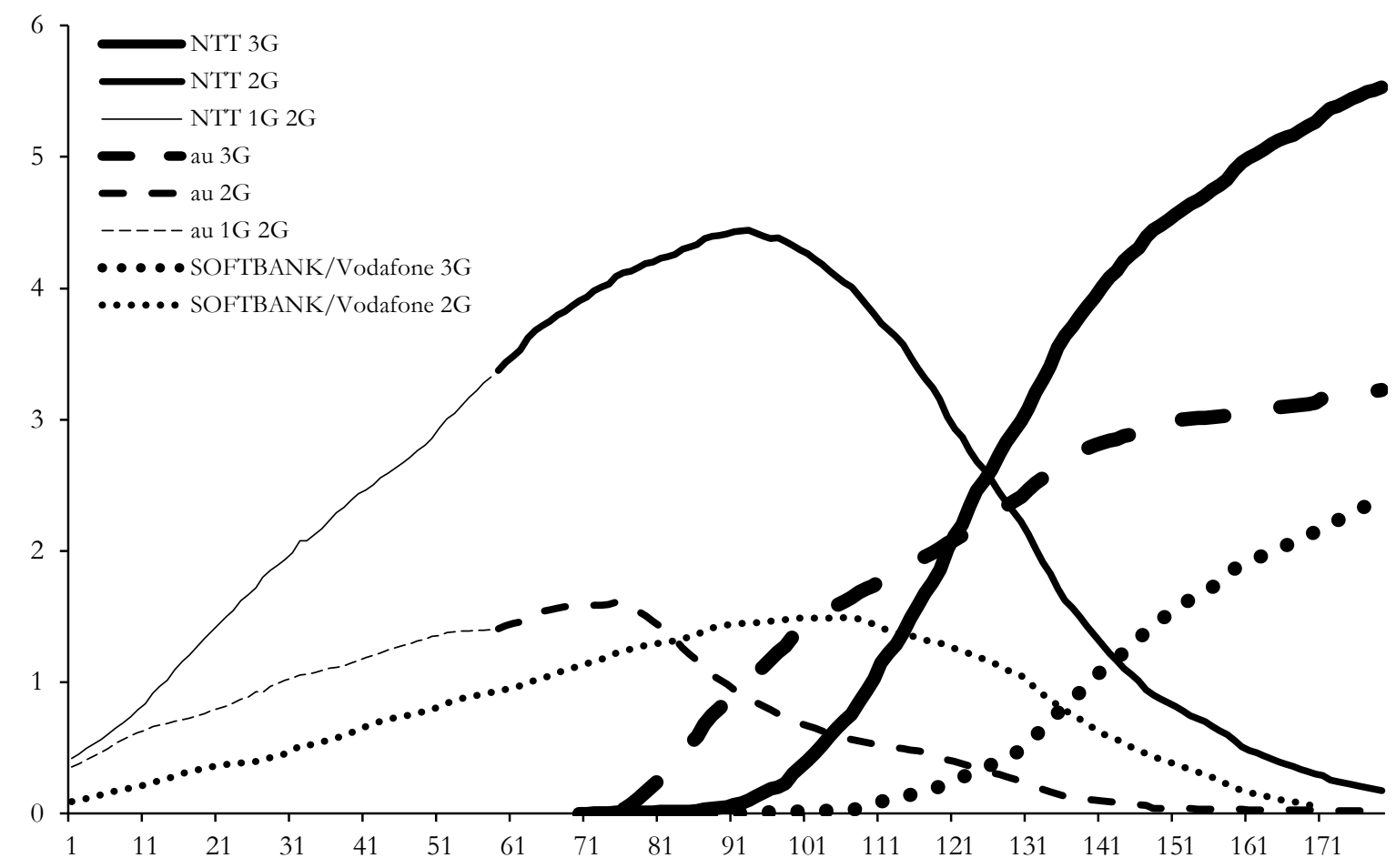

Figure 1: Mobile Telecommunications Service Subscribers in Japan (Units in $\mathbf{1 0}^{\mathbf{7}}$ )

\subsection{Model Estimation}

For parameter estimation, we employed a genetic algorithm (Venkatesan et al., 2004), as this technique has been reported to give a higher probability of reaching optimum global solutions when the targeted model is inherently nonlinear and contains a large number of parameters (Del Moral et al., 2001). The application of this technique for new product diffusion models had been examined by Venkatesan et al. (2004). After substituting Equations (11) (13) - (18) into Equation (9) (or into Equation (10)), we estimated the parameters in the latter by minimizing the function

$$
\sum_{k=1}^{K} \sum_{l=1}^{L} \sum_{t=0}^{T}\left(\hat{S}_{k, l}(t)-S_{k, l}(t)\right)^{2}
$$

where $S_{k, l}(t)$ was the actual number of subscribers of brand $k$ generation $l$ at time $t$ and $\hat{S}_{k, l}(t)$ was the data predicted by the model. We ran the genetic algorithm tool in MATLAB with the following settings. The population size of the estimation was set as 500 (i.e., 500 sample solution vectors were generated for each iteration); the probabilities of crossover and mutation were set at the software's default values; and the estimation stopping rule was as follows: terminate if there is no improvement (less than 1E-12) in the objective function for 100 consecutive generations. We then ran the case estimation for 100 times repeatedly. The 
reported values in this study are those that produced the best fit from the 100 estimation repeats, and the standard deviations were those obtained from the 100 repeat estimates.

Our suggested model requires the estimation of 17 parameters for the case of three brands and three generations; i.e., nine parameters for the unique market potential (i.e., $m$ ) of each generation of each brand; three parameters for $p$ and three for $q$, since three brands were studied; plus parameters $b$ and $c$. In fact, the parameter number could be further reduced for this case. We set the market potential of each brand's first generation as a minimal value in the estimation $\left(m_{1,1}=m_{2,1}=m_{3,1}=0.0001 \times 10^{7}\right)$, as the historical data showed that the market penetration of the first generation was extremely low in the Japanese market (and also in those of other countries) compared with that of the following generations. We also used the Norton-Bass model to estimate and fit the aggregated data in terms of generations. The reported total market potential for the first generation was approximately $0.0001 \times 10^{7}$, which confirmed our assumption and indicated a nominal impact on the overall dynamics of the studied telecommunications market. Therefore, the number of parameters actually estimated in our empirical study was 14. In addition, as NTT and Softbank used the same telecommunication standards during the studied period, these two brands could be considered as having the same innovation and imitation effects $\left(p_{1}=p_{3}\right.$ and $\left.q_{1}=q_{3}\right)$, which would further reduce the number of parameters to 12 . Therefore, we estimated the suggested model with both settings and compared the results.

\subsection{Model Fit Results and Discussions}

Figure 2 provides a graphical representation of our proposed new model's fit to the actual data under the 14 parameter setting, due to the similar performance between the two settings. The graphical results indicate that our suggested model provides an excellent fit to the actual data. Table 3 reports the model fit statistics of both settings using the Sum of Squared Errors (SSE) and Mean Absolute Error (MAE) methods.

Overall, the comparison shows that, under the 14 parameter setting, the suggested model (i.e., independent $p$ and $q$ values for NTT and Softbank) only performs slightly better than it does under the 12 parameter one (i.e., same $p$ and $q$ values for NTT and Softbank). Under the former, the reported values of $p_{1}$ and $q_{1}$ are similar to the values of $p_{3}$ and $q_{3}: 0.0035$ and 0.0550 , compared to 0.0047 and 0.0537 . This confirms our assumption that NTT and Softbank could be assigned similar $p$ and $q$ values (i.e., $p_{1}=p_{3}$ and $q_{1}=q_{3}$ ) in order to reduce model complexity. 
As the new model was developed based on the Norton-Bass one, with additional consideration given to the cross-brand diffusion and communication effects, we also introduced the Norton-Bass model as a benchmark. To be more specific, we used the latter model to fit the market dynamics of NTT DoCoMo, au, and Softbank, respectively, under the assumption that no brand competition existed. A new product diffusion model incorporating brand competition (see examples in our literature review) could also have been suggested as a benchmark; however, without giving further consideration to customer dis-adoption behaviours (in this case, due to product upgrading), such a model would not have effectively explained why the cumulative number of users started to decline after certain time points (i.e., when a new generation was introduced). As indicated in our literature review, although the multi-categories and multi-generational model developed by Kim et al. (2000) could have been considered as another benchmark, this would have required 24 parameters (for three brands and three generations) to be estimated and would have needed additional data inputs for the market potential of each product (e.g., through individual Bass model estimation and expert interviews, as in those authors' paper), making the implementation impractical.

Table 3 also reports the comparison of the fit statistics of our model with those of the Norton-Bass one; this was effected by fitting the latter to the actual data for each of the generations of our studied brands, respectively. As we adopted the same setting -i.e., $m_{k, 1}=$ 0.0001 - the Norton-Bass model required the estimation of four parameters for each brand (i.e. $p_{k}, q_{k}, m_{k, 2}$, and $\left.m_{k, 3}\right)$, thus also requiring a total of 12 parameters to be estimated for our study case. The comparison results indicate that, under both settings, our new model offers a better fit than the Norton-Bass one, with significant improvements along both measures: SEE is reduced by more than $45 \%$ - from $25.7289 \times 10^{14}$ to $12.4326 \times 10^{14}$ and to $13.9544 \times 10^{14}$ and MAE is reduced by more than $25 \%$ - from $0.1338 \times 10^{7}$ to $0.8292 \times 10^{14}$ and to $0.1001 \times$ $10^{7}$. In terms of individual generations and brands in the product category, the suggested model proved to be superior in most cases, although the Norton-Bass one produced more accurate results for au3G and for NTT1G2G in terms of MAE. 


\section{Estimated Parameters (14 parameters)}

NTT

au

$\begin{array}{lclc} & 0.0035 & & 0.0440 \\ p_{1} & (0.0015) & p_{2} & (0.0019) \\ & 0.0550 & & 0.0001 \\ q_{1} & (0.0055) & q_{2} & (0.0000) \\ & 3.9727 & & 1.2114 \\ m_{1,2} & (0.0210) & m_{2,2} & (0.0039) \\ & 1.5898 & & 1.8415 \\ m_{1,3} & (0.0021) & m_{2,3} & (0.0065)\end{array}$

SOFTBANK

$\begin{array}{lccc}p_{3} & 0.0047 & & -0.1903 \\ & (0.0019) & & (0.0027) \\ q_{3} & 0.0537 & & -0.2901 \\ & (0.0057) & c & (0.1064) \\ m_{3,2} & 1.9268 & & \\ & (0.0023) & & \\ m_{3,3} & 1.2465 & & \end{array}$

Values in brackets are the standard deviation of the 100 repeats;

Unit in $10^{7}$ for market potentials;

\section{Model Fit}

\begin{tabular}{ccccccc} 
Fitted Curves & Norton-Bass Model & \multicolumn{2}{c}{$\begin{array}{c}\text { Suggested Model } \\
\text { (14 parameters) }\end{array}$} & \multicolumn{2}{c}{$\begin{array}{c}\text { Suggested Model } \\
\text { (12 parameters) }\end{array}$} \\
& SSE & MAE & SSE & MAE & SSE & MAE \\
NTT1G2G & 4.8227 & 0.2221 & 4.0326 & 0.2231 & 4.4125 & 0.2275 \\
NTT2G & 6.9832 & 0.1875 & 2.9683 & 0.1355 & 2.7051 & 0.1255 \\
NTT3G & 4.4171 & 0.1724 & 0.8737 & 0.0742 & 0.9315 & 0.0725 \\
au1G2G & 2.0492 & 0.1602 & 0.3642 & 0.0736 & 0.4419 & 0.0784 \\
au2G & 2.2949 & 0.1136 & 1.1183 & 0.0815 & 1.1623 & 0.0826 \\
au3G & 0.4835 & 0.0543 & 1.2877 & 0.1007 & 1.1311 & 0.0950 \\
SOFTBANK2G & 4.3970 & 0.1404 & 1.5251 & 0.0823 & 2.8418 & 0.1118 \\
SOFTBANK3G & 0.2813 & 0.0443 & 0.2627 & 0.0382 & 0.3281 & 0.0450 \\
OVERALL & $\mathbf{2 5 . 7 2 8 9}$ & $\mathbf{0 . 1 3 3 8}$ & $\mathbf{1 2 . 4 3 2 6}$ & $\mathbf{0 . 8 0 9 2}$ & $\mathbf{1 3 . 9 5 4 4}$ & $\mathbf{0 . 1 0 1 1}$ \\
The unit for SSE results is $10^{14} ;$ & & & & & \\
The unit for MAE results is $10^{7} ;$ & & & & & \\
\hline
\end{tabular}



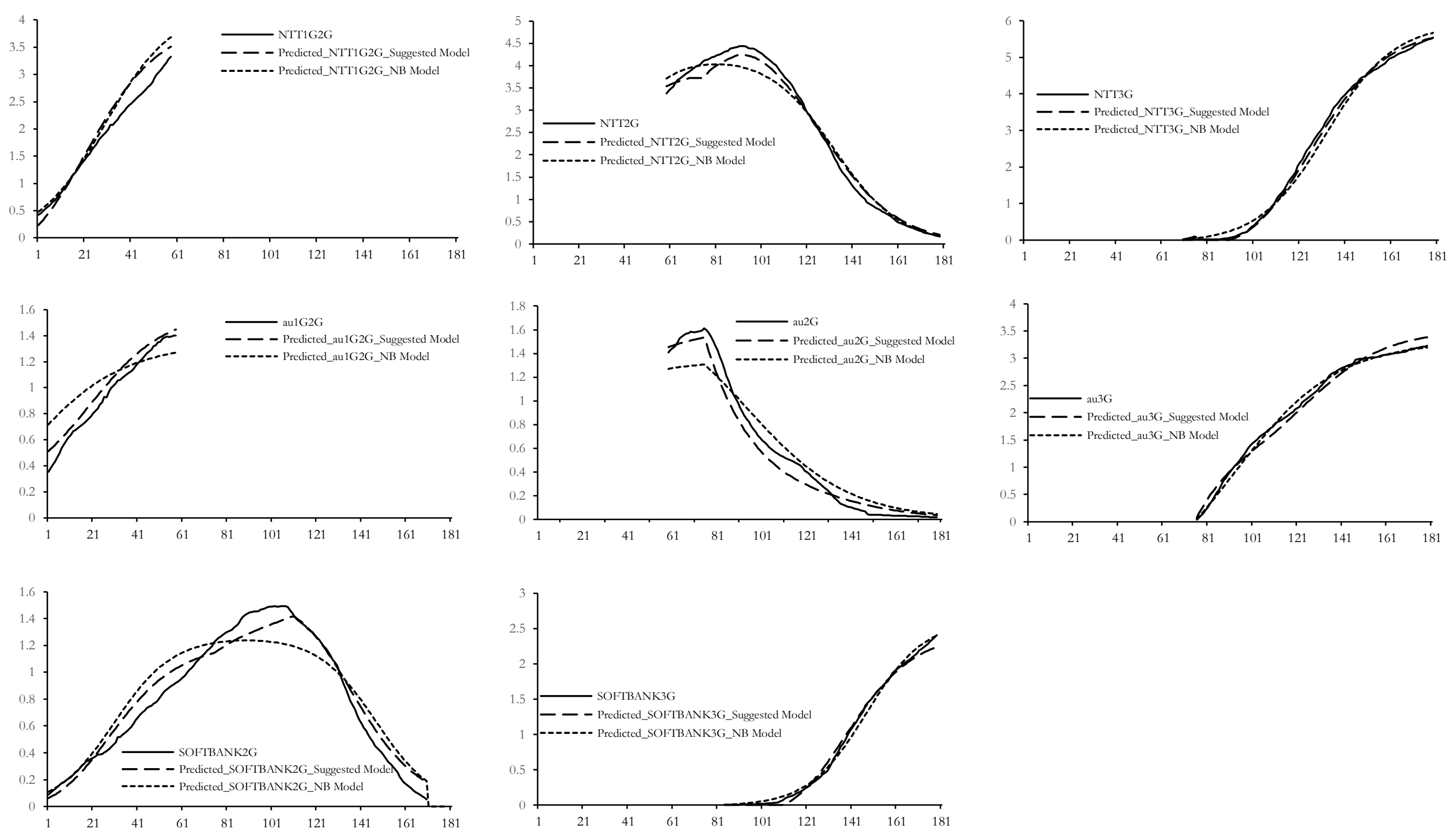

Figure 2: Model Fit: Suggested Model (14 parameters), Norton-Bass Model and Actual Data (Units in 10 ${ }^{\mathbf{7}}$ ) 
We can derive some further findings from our model fit results and we provide the below discussions based on the first setting of the suggested model. First, the telecommunication standards adopted by NTT and Softbank received poorer market responses than the au one in terms of the innovation effect $\left(p_{1}=0.0035\right.$ and $p_{2}=0.0047$, as opposed to $\left.p_{2}=0.0440\right)$. As this effect wields greater influence during the initial diffusion stages, the estimation result reported here may partly explain why au's product sales had taken off much faster than those of NTT and Softbank. However, NTT and Softbank's mobile telecommunication standards had benefited more from the imitation effect $\left(q_{1}=0.0550\right.$ and $q_{3}=0.0537$, as opposed to $\left.q_{2}=0.0001\right)$, which had outweighed their take-off disadvantages in later stages. Second, the reported values of the $m_{k, l}$ parameter indicate that the release of new generations had constantly increased each brand's market potential. Second, the estimation of $m_{k, l}$ shows that NTT had established its leadership in the market based on the success of its $2 \mathrm{G}$ service $\left(m_{1,2}=\right.$ $3.9727 \times 10^{7}, m_{2,2}=1.2114 \times 10^{7}$, and $\left.m_{3,2}=1.9268 \times 10^{7}\right)$. Although au had caught up during the $3 \mathrm{G}$ service standard war $\left(m_{1,3}=1.5898 \times 10^{7}, m_{2,3}=1.8415 \times 10^{7}\right.$, and $m_{3,3}=$ $1.2465 \times 10^{7}$ ), NTT had retained the larger market share due to its customer base, longaccumulated from previous generations.

Third, the reported cross-brand diffusion and cross-brand communication effects are both negative. Thus, the estimation result suggests that, in the Japanese wireless communications market, brand competition has a negative impact on both product diffusion rates and actual market growth. Perhaps this is because the coexistence of different network service standards in the market confuses, rather than enhancing, customer understandings, delaying their decisions to adopt and upgrade. Some additional insights into the initial diffusion stages of each product, which were not available by analysing prior diffusion models, can be provided by the reported estimation of $b$ and $c$. We know that the value of $F_{2, l}$ was significantly higher than $F_{1, l}$ and $F_{2, l}$ during each generation's initial stage, because: 1 ) parameter $p$ was the most important for the value of $F$ during this period; and 2) $p_{1} \& p_{3}<p_{2}$. When $c<0$, we can easily see from Equation (16) that the value of $x_{2, l}(t)$ (i.e., the diffusion rate of the au products) should be significantly higher than $x_{1, l}(t)$ and $x_{3, l}(t)$ (i.e., the diffusion rates of the NTT and SOFTBANK products) during this period. Although the market growth of all three brands had been delayed by cross-brand diffusion effects $(b<0$ in Equation (13)), we could have expected that au would have suffered less delay than either NTT or SOFTBANK. In other words, the negative values of parameters $b$ and $c$ can provide further explanations as to why NTT's and SOFTBANK's products had recorded a 
comparatively slower initial growth, while au's had taken off much more quickly. The curves presented in Figure 2- particularly those of NTT3G, au3G, and SOFTBANK3G - support these findings.

\section{Model Validation Based on Predictive Performance}

To further examine the predictive validity of our proposed model, we followed an approach similar to that of Decker et al. (2010); i.e., to first divide the data set into a calibration period and a forecasting one. The calibration period data were then used to estimate the model parameters used to predict market growth in the forecasting period. We maintained the parameter setting in the model fit analysis; in particular, we adopted the setting that considered NTT and Softbank as having the same innovation and imitation effects $\left(p_{1}=p_{3}\right.$ and $q_{1}=q_{3}$ ), because they used the same telecommunications standards during the studied period and because the setting and assumption had been empirically supported in our model fit analysis. We acknowledge that this setting may have slightly weakened the forecasting performance of the suggested model. However, it did enable the estimation of 12 parameters by the model and the benchmark; by using the same number of estimated parameters, a better sense was made of how the new model compared with the Norton-Bass one.

The estimation techniques were consistent with those used previously in the model fit analysis. We conducted six sets of tests to forecast the performance of the market's three main network services during the period studied using different forecasting periods (data points) for 5, 10, 15, 20, 25, and 30 months ahead-which yielded the NTT3G, au3G, and SOFTBANK3G forecast curves. As they had been widely accepted in previous studies of new product diffusion models, we introduced the Mean Absolute Percentage Error (MAPE) and Mean Absolute Error (MAE) to demonstrate the model' predictive performance. These two values are based on scale-dependent measures and percentage errors, respectively (Hyndman et al., 2006). As a third measure, we also introduced the median absolute percentage error (MdAPE), which had been recommended by Armstrong et al. (1992) and Tashman (2000) over MAPE. To gain a better sense of our model's forecasting performance for the overall market dynamics, we also calculate the MAPE, MAE and MdAPE for the three curves over the whole duration of each of the forecasting periods.

Table 4 reports the results, showing that our proposed model performed well in all six forecasting periods, and showed itself capable of accurately predicting market dynamics even 
in the longest term forecasting (30 months ahead) $(M A P E=5.016 \%)$. We also compare our model's forecasting results with those of the Norton-Bass one, and Table 4 provides the two models' comparative predictive results. In terms of individual brands, the Norton-Bass model performed better in predicting au3G's market growth, but the new model demonstrated superior performance in the cases of NTT3G and SOFTBANK3G - a finding that echoes the model fit results, where the Norton-Bass model also exhibited better performance in the au3G case. In terms of each forecasting period, the Norton-Bass model shows modest superiority over the suggested model over relatively short forecasting periods, as shown by the results for the five months ahead period. However, as the forecasting periods lengthen, the suggested model becomes increasingly superior. In the 30 months ahead forecasting period, its reported MAPE, MAPE and MdAPE are 5.016\%, 0.1695, and 0.0552, significantly better than those produced by the Norton-Bass model $(9.854 \%, 0.3536$, and 0.1055$)$.

Table 4: Model Performance in Forecasting I

\begin{tabular}{|c|c|c|c|c|c|c|c|}
\hline \multirow{3}{*}{$\begin{array}{c}\text { Predicted } \\
\text { Periods }\end{array}$} & \multirow{3}{*}{$\begin{array}{c}\text { Predicted } \\
\text { Curves }\end{array}$} & \multicolumn{6}{|c|}{ Forecasting Performance } \\
\hline & & \multicolumn{3}{|c|}{ Norton-Bass Model } & \multicolumn{3}{|c|}{ Suggested Model } \\
\hline & & MAPE & MAE & MdAPE & MAPE & MAE & MdAPE \\
\hline \multirow[t]{4}{*}{5 Periods } & NTT3G & $3.300 \%$ & 0.1811 & 0.0324 & $0.638 \%$ & 0.0350 & 0.0057 \\
\hline & au3G & $0.802 \%$ & 0.0258 & 0.0082 & $5.523 \%$ & 0.1773 & 0.0553 \\
\hline & SOFTBANK3G & $1.249 \%$ & 0.0289 & 0.0125 & $0.999 \%$ & 0.0238 & 0.0092 \\
\hline & OVERALL & $1.784 \%$ & 0.0786 & 0.0177 & $2.387 \%$ & 0.0787 & 0.0234 \\
\hline \multirow[t]{4}{*}{10 Periods } & NTT3G & $4.542 \%$ & 0.2459 & 0.0447 & $1.385 \%$ & 0.0747 & 0.0129 \\
\hline & au3G & $0.692 \%$ & 0.0221 & 0.0068 & $6.550 \%$ & 0.2088 & 0.0651 \\
\hline & SOFTBANK3G & $3.547 \%$ & 0.0799 & 0.0398 & $1.134 \%$ & 0.0106 & 0.0116 \\
\hline & OVERALL & $2.927 \%$ & 0.1160 & 0.0304 & $3.023 \%$ & 0.0980 & 0.0299 \\
\hline \multirow[t]{4}{*}{15 Periods } & NTT3G & $6.371 \%$ & 0.3395 & 0.0611 & $2.505 \%$ & 0.1329 & 0.0218 \\
\hline & au3G & $0.575 \%$ & 0.0182 & 0.0056 & $8.079 \%$ & 0.2553 & 0.0803 \\
\hline & SOFTBANK3G & $6.846 \%$ & 0.1504 & 0.0710 & $2.386 \%$ & 0.0504 & 0.0259 \\
\hline & OVERALL & $4.597 \%$ & 0.1694 & 0.0459 & $4.323 \%$ & 0.1462 & 0.0427 \\
\hline \multirow[t]{4}{*}{20 Periods } & NTT3G & $8.339 \%$ & 0.4385 & 0.0820 & $3.527 \%$ & 0.1846 & 0.0373 \\
\hline & au3G & $0.503 \%$ & 0.0158 & 0.0053 & $9.526 \%$ & 0.2991 & 0.0972 \\
\hline & SOFTBANK3G & $9.770 \%$ & 0.2110 & 0.1054 & $3.653 \%$ & 0.0776 & 0.0385 \\
\hline & OVERALL & $6.204 \%$ & 0.2218 & 0.0642 & $5.569 \%$ & 0.1871 & 0.0577 \\
\hline \multirow[t]{4}{*}{25 Periods } & NTT3G & $11.215 \%$ & 0.5800 & 0.1116 & $4.695 \%$ & 0.2417 & 0.0484 \\
\hline & au3G & $0.444 \%$ & 0.0138 & 0.0042 & $10.873 \%$ & 0.3395 & 0.1151 \\
\hline & SOFTBANK3G & $13.318 \%$ & 0.2823 & 0.1552 & $5.828 \%$ & 0.1208 & 0.0598 \\
\hline & OVERALL & $8.326 \%$ & 0.2920 & 0.0903 & $7.132 \%$ & 0.2340 & 0.0744 \\
\hline \multirow[t]{4}{*}{30 Periods } & NTT3G & $14.447 \%$ & 0.7368 & 0.1495 & $3.767 \%$ & 0.1908 & 0.0399 \\
\hline & au3G & $0.565 \%$ & 0.0174 & 0.0048 & $8.141 \%$ & 0.2534 & 0.0925 \\
\hline & SOFTBANK3G & $14.550 \%$ & 0.3066 & 0.1622 & $3.140 \%$ & 0.0643 & 0.0331 \\
\hline & OVERALL & $9.854 \%$ & 0.3536 & 0.1055 & $5.016 \%$ & 0.1695 & 0.0552 \\
\hline \multicolumn{8}{|c|}{ The unit for MAE results is $10^{7}$. } \\
\hline
\end{tabular}


Table 5: Model Performance in Forecasting II

\begin{tabular}{|c|c|c|c|c|c|c|c|}
\hline \multirow{3}{*}{$\begin{array}{c}\text { Fit } \\
\text { Periods }\end{array}$} & \multirow{3}{*}{$\begin{array}{l}\text { Predicted } \\
\text { Curves }\end{array}$} & \multicolumn{6}{|c|}{ Forecasting Performance } \\
\hline & & \multicolumn{3}{|c|}{ Norton-Bass Model } & \multicolumn{3}{|c|}{ Suggested Model } \\
\hline & & MAPE & MAE & MdAPE & MAPE & MAE & MdAPE \\
\hline \multirow[t]{5}{*}{174 Periods } & 5 Periods & $1.784 \%$ & 0.0786 & 0.177 & $2.387 \%$ & 0.0787 & 0.0234 \\
\hline & 10 Periods & --- & --- & --- & --- & --- & --- \\
\hline & 15 Periods & --- & --- & --- & --- & --- & --- \\
\hline & 20 Periods & --- & --- & --- & --- & --- & --- \\
\hline & 25 Periods & --- & --- & --- & --- & --- & --- \\
\hline \multirow[t]{5}{*}{169 Periods } & 5 Periods & $3.269 \%$ & 0.1247 & 0.0316 & $3.236 \%$ & 0.1107 & 0.0308 \\
\hline & 10 Periods & $2.927 \%$ & 0.1160 & 0.0304 & $3.015 \%$ & 0.0974 & 0.0299 \\
\hline & 15 Periods & --- & --- & --- & --- & --- & --- \\
\hline & 20 Periods & --- & --- & --- & --- & --- & --- \\
\hline & 25 Periods & --- & --- & --- & --- & --- & --- \\
\hline \multirow[t]{5}{*}{164 Periods } & 5 Periods & $4.945 \%$ & 0.1768 & 0.0509 & $5.012 \%$ & 0.1666 & 0.0506 \\
\hline & 10 Periods & $4.833 \%$ & 0.1745 & 0.0487 & $4.697 \%$ & 0.1572 & 0.0476 \\
\hline & 15 Periods & $4.597 \%$ & 0.1694 & 0.0459 & $4.323 \%$ & 0.1462 & 0.0427 \\
\hline & 20 Periods & --- & --- & --- & --- & --- & --- \\
\hline & 25 Periods & --- & --- & --- & --- & --- & --- \\
\hline \multirow[t]{5}{*}{159 Periods } & 5 Periods & $5.166 \%$ & 0.1858 & 0.0527 & $5.227 \%$ & 0.1739 & 0.0532 \\
\hline & 10 Periods & $5.968 \%$ & 0.2107 & 0.0599 & $5.791 \%$ & 0.1917 & 0.0580 \\
\hline & 15 Periods & $6.203 \%$ & 0.2193 & 0.0662 & $5.780 \%$ & 0.1922 & 0.0586 \\
\hline & 20 Periods & $6.204 \%$ & 0.2218 & 0.0642 & $5.569 \%$ & 0.1871 & 0.0577 \\
\hline & 25 Periods & --- & --- & --- & --- & --- & --- \\
\hline \multirow[t]{5}{*}{154 Periods } & 5 Periods & $6.082 \%$ & 0.2158 & 0.0616 & $6.201 \%$ & 0.1972 & 0.0633 \\
\hline & 10 Periods & $6.771 \%$ & 0.2383 & 0.0658 & $6.525 \%$ & 0.2091 & 0.0651 \\
\hline & 15 Periods & $7.646 \%$ & 0.2662 & 0.0756 & $7.049 \%$ & 0.2269 & 0.0702 \\
\hline & 20 Periods & $8.107 \%$ & 0.2822 & 0.0827 & $7.190 \%$ & 0.2333 & 0.0742 \\
\hline & 25 Periods & $8.326 \%$ & 0.2920 & 0.0903 & $7.132 \%$ & 0.2340 & 0.0744 \\
\hline \multirow[t]{5}{*}{149 Periods } & 5 Periods & $5.156 \%$ & 0.2008 & 0.0510 & $2.635 \%$ & 0.0912 & 0.0270 \\
\hline & 10 Periods & $6.520 \%$ & 0.2427 & 0.0679 & $3.686 \%$ & 0.1249 & 0.0378 \\
\hline & 15 Periods & $7.524 \%$ & 0.2750 & 0.0811 & $4.236 \%$ & 0.1427 & 0.0457 \\
\hline & 20 Periods & $8.607 \%$ & 0.3095 & 0.0855 & $4.795 \%$ & 0.1606 & 0.0499 \\
\hline & 25 Periods & $9.355 \%$ & 0.3348 & 0.0966 & $5.011 \%$ & 0.1681 & 0.0543 \\
\hline
\end{tabular}

To further support the above findings and in order to provide a more comprehensive comparison, in Table 5, we report the new model and the benchmark's overall forecasting performance of the curves under more fitting periods and predicted periods (Tashman, 2000). For instance, we maintain the forecasting origin as 149 fit periods and report the models' forecasting performance for 5, 10, 15, 20, and 25 predicted periods (i.e., a fixed-origin approach); and we successively update the forecasting origin from 149 fit periods to 174 fit periods and report the models' forecasting performance for 5 predicted periods (i.e., a rollingorigin approach). The reported data again affirm the superior predictive performance of our 
suggested model in long-term forecasting; they also provide further evidence for the significance of considering brand competition and generational substitution simultaneously when modelling and analysing new product market performance. For instance, in terms of the 25 predicted periods under 149 and 154 fitting periods, the reported MdAPE values by the new model are 0.0543 and 0.0744 , compared with the those reported by the Norton-Bass model (i.e., 0.0966 and 0.0903). Again, given our model setting in the forecasting analysis, it is important to note that, compared with the Norton-Bass model, its improved predictive ability is not based on increased numbers of estimation parameters, as we used same numbers for both models in this forecasting analysis.

\section{Conclusions}

It is critical for firms to understand, monitor, and predict the market growth of their new products (Tseng, 2008) in order to realize their full commercial potential and create competitive advantage over their rivals. In today's competitive market, products can mostly be differentiated by numbers of competing brands and successive generations; we offer a new product diffusion model for this context.

This study offers several original implications for both theory and practice. First, although the prior literature had emphasized and analysed the impacts of brand competition and of generational substitution on the market performance of new products, it had only dealt with each separately (Bass, 2004; Chatterjee et al., 2000; Meade et al., 2006; Peres et al., 2010; van Oorschot et al., 2018). Building on prior diffusion studies, our model considers customer upgrading between successive generations; enables customer switching between competing brands; and recognizes the cross-brand diffusion and communication effects on the market growth process. Based on the suggested model and its empirical analysis, we are able to affirm the simultaneous coexistence of both brand competition and generation substitution, and the importance of appreciating this coexistence to understand the overall market dynamics of product categories and the market performance of individual brands and generations. In addition, we argue that our model can provide valuable empirical evidence to help managers quantify these influences and thus aid their decision-making. For instance, by applying our model to the case of Japanese telecommunications services, we observed and assessed a significant and negative impact of brand competition on the growth of new product category users, and on the process of generation substitution. 
Second, one of the main abilities of new product diffusion models is to estimate potentials for market forecasting and planning (Bass, 2004; Peres et al., 2010). As conventional diffusion models are often homogeneous in terms of brands and/or generations, their estimated market potential results are usually also aggregated. However, in real-life practice, firms may be more concerned about the market potential of specific products. Through the estimation of $m_{k, l}$., the suggested model valuably satisfies the need to segment and specify products' estimated market potential in terms of market niches for each brand and each generation.

Third, the new model reverts to the Norton-Bass one (Norton et al., 1987) when the crossbrand diffusion and cross-brand communication effects are eliminated, which is an important advantage, as the Norton-Bass model remains the most cited and widely applied multigenerational product diffusion model to date. Moreover, the superior performance of the new model over the Norton-Bass one in the empirical analysis provides further evidence of the validity and significance of the coexistence of brand competition and generation substitution.

Fourth, the complexity of the diffusion context increases with the introduction of more influences, such as multi-brand and multi-generation. Therefore, many recent new product diffusion models sacrifice their forecasting abilities and rely on simulations (Nejad, 2016) to understand the phenomenon. By applying it to the Japanese telecommunications services market, we have shown that our suggested model is capable of providing reliable forecasting for each brand, each generation, and for overall market dynamics, The new model demonstrates especially accurate and reliable performance when the forecasting period is relatively long. The model and its results also highlight the need for firms to adjust their marketing strategies according to any market changes resulting from both the entry/exit of competing brands and technological industry advances. This study can therefore serve as a valuable reference to help firms make important decisions regarding the marketing of multigenerational products in a competitive market.

Last but not least, we built our model based on the conceptual foundation of prior new product diffusion models (i.e., multigenerational diffusion and competitive diffusion models) that had been applied in various high-technology industries such as computing, display monitors, telecommunications, and home entertainment. We therefore expect our new model to have extensive application potential in those industries, and perhaps in many others that involve both brand competition and technological substitution. 


\subsection{Limitations and Future Directions}

Although we view this study as an important step in the new product growth literature, it does have limitations that indicate areas for further research. First, we implemented the proposed new model in a case drawn from the telecommunications industry - future studies should thus introduce more empirical data to extend its validity and its results to other product categories and to other industries. Second, the introduction of strategic and managerial variables (e.g., price and advertisement) could further enhance the new model's accuracy and thus its wider value (Feng et al., 2019; Samuel Sale et al., 2017). A potential starting point could involve replacing Equations (17) and (18) by using the generalized Bass model (Bass et al., 1994). Third, future research could also study 'leapfrogging' behaviours to widen the value of the suggested model, either by introducing new coefficients for leapfrogging (e.g., Mahajan et al. (1996)), or by re-structuring it based on the generalized Norton-Bass model (Jiang et al., 2012).

\section{References}

Albuquerque P, Bronnenberg BJ, Corbett CJ. 2007. A Spatiotemporal Analysis of the Global Diffusion of ISO 9000 and ISO 14000 Certification. Management Science 53(3): 451-468.

Armstrong JS, Collopy F. 1992. Error measures for generalizing about forecasting methods: Empirical comparisons. International Journal of Forecasting 8(1): 69-80.

Aytac B, Wu SD. 2011. Modelling high-tech product life cycles with short-term demand information: a case study. Journal of the Operational Research Society 62(3): 425-432.

Bass FM. 1969. A New Product Growth for Model Consumer Durables. Management Science 15(5): 215-227.

Bass FM. 2004. Comments on "A New Product Growth for Model Consumer Durables": The Bass Model. Management Science 50(12): 1833-1840.

Bass FM, Krishnan TV, Jain DC. 1994. Why the Bass Model Fits without Decision Variables. Marketing Science 13(3): 203-223.

Chatterjee R, Eliashberg J, Rao VR. 2000. Dynamic Models Incorporating Competition. In New Product Diffusion Models. Mahajan V, Muller E, Wind Y (eds.), Kluwer Academic Publishers: New York.

Decker R, Gnibba-Yukawa K. 2010. Sales Forecasting in High-Technology Markets: A Utility-Based Approach. Journal of Product Innovation Management 27(1): 115-129.

Del Moral P, Miclo L. 2001. Asymptotic Results for Genetic Algorithms with Applications to Nonlinear Estimation. In Theoretical Aspects of Evolutionary Computation. Kallel L, Naudts B, Rogers A (eds.), Springer-Verlag: Berlin, Germany.

Feng L, Chan Y-L. 2019. Joint pricing and production decisions for new products with learning curve effects under upstream and downstream trade credits. European Journal of Operational Research 272(3): 905-913.

Griliches Z. 1957. Hybrid Corn: An Exploration in the Economics of Technological Change. Econometrica 25(4): 501-522. 
Guo Z, Chen J. 2018. Multigeneration Product Diffusion in the Presence of Strategic Consumers. Information Systems Research 29(1): 206-224.

Guseo R, Mortarino C. 2012. Sequential market entries and competition modelling in multi-innovation diffusions. European Journal of Operational Research 216(3): 658-667.

Hyndman RJ, Koehler AB. 2006. Another look at measures of forecast accuracy. International Journal of Forecasting 22(4): 679-688.

Islam T, Meade N. 1997. The Diffusion of Successive Generations of a Technology: A More General Model. Technological Forecasting and Social Change 56: 49-60.

Jiang Z, Jain DC. 2012. A Generalized Norton-Bass Model for Multigeneration Diffusion. Management Science 58(10): 1887-1897.

Jun DB, Kim Ji. 2011. A choice-based multi-product diffusion model incorporating replacement demand. Technological Forecasting and Social Change 78(4): 674-689.

Kiesling E, Günther M, Stummer C, Wakolbinger L. 2012. Agent-based simulation of innovation diffusion: a review. Central European Journal of Operations Research 20(2): 183-230.

Kim N, Chang DR, Shocker AD. 2000. Modeling Intercategory and Generational Dynamics for a Growing Information Technology Industry. Management Science 46(4): 496-512.

Kim S-H, Srinivasan V. 2003. A Multiattribute Model of the Timing of Buyers' Upgrading to Improved Versions of High Technology Products, Graduate School of Business.

Kreng VB, Wang BJ. 2013. An innovation diffusion of successive generations by system dynamics - An empirical study of Nike Golf Company. Technological Forecasting and Social Change 80(1): 77-87.

Krishnan TV, Bass FM, Kumar V. 2000. Impact of a Late Entrant on the Diffusion of a New Product/Service. Journal of Marketing Research 37(2): 269-278.

Kushida K. 2002. The Japanese Wireless Telecommunications Industry: innovation, organizational structures, and government policy. Stanford Journal of East Asian Affairs 2(Spring 2002).

Libai B, Muller E, Peres R. 2009a. The Diffusion of Services. Journal of Marketing Research 46(2): 163-175.

Libai B, Muller E, Peres R. 2009b. The Role of Within-Brand and Cross-Brand Communications in Competitive Growth. Journal of Marketing 73(3): 19-34.

Liu H. 2010. Dynamics of Pricing in the Video Game Console Market: Skimming or Penetration? Journal of Marketing Research 47(3): 428-443.

Mahajan V, Muller E. 1996. Timing, diffusion, and substitution of successive generations of technological innovations: The IBM mainframe case. Technological Forecasting and Social Change 51(2): 109-132.

Meade N, Islam T. 2006. Modelling and forecasting the diffusion of innovation - A 25year review. International Journal of Forecasting 22(3): 519-545.

Michalakelis C, Varoutas D, Sphicopoulos T. 2010. Innovation diffusion with generation substitution effects. Technological Forecasting and Social Change 77(4): 541-557.

Negahban A, Yilmaz L, Nall T. 2014. Managing production level in new product diffusion: an agent-based simulation approach. International Journal of Production Research 52(17): 49504966.

Nejad MG. 2016. On the contributions and the validation of an agent-based simulation model of innovation diffusion. European Journal of Marketing 50(3/4): 647-657.

Norton JA, Bass FM. 1987. A Diffusion Theory Model of Adoption and Substitution for Successive Generations of High-Technology Products. Management Science 33(9): 1069-1086.

Pae JH, Lehmann DR. 2003. Multigeneration innovation diffusion: The impact of intergeneration time. Journal of the Academy of Marketing Science 31(1): 36.

Parker P, Gatignon H. 1994. Specifying competitive effects in diffusion models: An empirical analysis. International Journal of Research in Marketing 11(1): 17-39. 
Peres R, Muller E, Mahajan V. 2010. Innovation diffusion and new product growth models: A critical review and research directions. International Journal of Research in Marketing 27(2): 91-106.

Samuel Sale R, Mesak HI, Inman RA. 2017. A dynamic marketing-operations interface model of new product updates. European Journal of Operational Research 257(1): 233-242.

Savin S, Terwiesch C. 2005. Optimal Product Launch Times in a Duopoly: Balancing LifeCycle Revenues with Product Cost. Operations Research 53(1): 26-47.

Stremersch S, Muller E, Peres R. 2010. Does new product growth accelerate across technology generations? Marketing Letters 21(2): 103-120.

Stummer C, Kiesling E, Günther M, Vetschera R. 2015. Innovation diffusion of repeat purchase products in a competitive market: An agent-based simulation approach. European Journal of Operational Research 245(1): 157-167.

Tashman LJ. 2000. Out-of-sample tests of forecasting accuracy: an analysis and review. International Journal of Forecasting 16(4): 437-450.

Tsai B-H. 2013. Predicting the diffusion of LCD TVs by incorporating price in the extended Gompertz model. Technological Forecasting and Social Change 80(1): 106-131.

Tseng FM. 2008. Quadratic interval innovation diffusion models for new product sales forecasting. Journal of the Operational Research Society 59(8): 1120-1127.

van Oorschot JAWH, Hofman E, Halman JIM. 2018. A bibliometric review of the innovation adoption literature. Technological Forecasting and Social Change 134: 1-21.

Venkatesan R, Krishnan TV, Kumar V. 2004. Evolutionary Estimation of Macro-Level Diffusion Models Using Genetic Algorithms: An Alternative to Nonlinear Least Squares. Marketing Science 23(3): 451-464.

Yan H-S, Ma K-P. 2011. Competitive diffusion process of repurchased products in knowledgeable manufacturing. European Journal of Operational Research 208(3): 243-252. 